\title{
Turn-amplitude analysis as a diagnostic test for myofascial syndrome in patients with chronic pelvic pain
}

\author{
Fernando Itza $\mathrm{PhD}^{1}$, Daniel Zarza $\mathrm{PhD}^{2}$, Jesus Salinas $\mathrm{PhD}^{3}$, Fernando Teba $\mathrm{PhD}^{4}$, Carmen Ximenez $\mathrm{PhD}^{5}$
}

F Itza, D Zarza, J Salinas, F Teba, C Ximenez. Turns-amplitude analysis as a diagnostic test for myofascial syndrome in patients with chronic pelvic pain. Pain Res Manag 2015;20(2):96-100.

BACKGROUND: Myofascial pain syndrome of the pelvic floor (MPSPF) is a common disease in the context of chronic pelvic pain (CPP); however, there is currently no gold-standard test to diagnose it.

OBJECTIVE: To validate the turns-amplitude analysis (TAA) as a diagnostic test for MPSPF in patients with CPP.

METHODS: A case-control study was performed, and patients were consecutively sampled within a specified period of time. A total of 128 patients were included: 64 patients with CPP ( 32 men and 32 women) and 64 control patients ( 32 men and 32 women). The same operator conducted all tests. Electromyography of the TAA is based on the collection of motor unit potentials that measure the number of changes in the signal and the mean amplitude of the changes. The electromyogram transfers the data to a graphical point cloud, which enables the patient's results to be compared with the results of the healthy subjects.

RESULTS: In patients and control subjects, the sensitivity and specificity of the proposed diagnostic test showed a marked clinical significance: the sensitivity was $83 \%$, and the specificity was $100 \%$. A positive predictive value of 1 (95\% CI 1 to 1$)$ and a negative predictive value of 0.85 (95\% CI 0.77 to 0.93 ) were observed.

CONCLUSION: TAA is a reliable diagnostic test to detect MPSPF. Further studies are needed to reproduce these results.

Key Words: Chronic pelvic pain; Diagnostic test; Myofascial syndrome; Neurophysiological test; Turns-amplitude analysis

M yofascial pain syndrome of the pelvic floor (MPSPF) is a common disease in the context of chronic pelvic pain (CPP) $(1,2)$. CPP is localized in the pelvic region and persists for at least six months (1). In the United States, approximately $12 \%$ of the general population is affected by CPP, and the lifetime prevalence is 33\% (3). Mathias et al (4) estimated the worldwide incidence to be between $2 \%$ and $16 \%$. CPP is more prevalent among women (5) compared with men (6). Studies have increasingly correlated MPSPF and CPP (7-9).

MPSPF can affect any muscle in the pelvic area or adjacent areas and is associated with urinary, gynecological, proctological, neurological and sexual dysfunctions. MPSPF has substantial symptomatic variability and, thus, reaching a rapid and precise diagnosis is difficult (10-16).

MPSPF is a regional pain neuromuscular disorder that affects muscles and fascia. The involved muscles develop trigger points $(\mathrm{TrPs})$ in their structure (17).

Authors have defined this type of symptomatology as short pelvic floor syndrome because the disease is associated with a loss of muscle length and consequent functional problems (18). Other authors have studied several nosological entities, presumably with different origins, and have found that they have MPSPF in common. These related

\section{L'analyse des inversions et de l'amplitude comme test diagnostique du syndrome myofascial chez les patients ayant des douleurs pelviennes chroniques}

HISTORIQUE : La douleur pelvienne chronique (DPC) s'associe souvent à un syndrome myofascial du plancher pelvien (SMPP). Cependant, il n'existe aucun test de référence pour le diagnostiquer.

OBJECTIF : Valider l'analyse des inversions et de l'amplitude (AIA) comme test diagnostique du SMPP chez les patients ayant des DPC.

MÉTHODOLOGIE : Dans le cadre d'une étude cas-témoins, les chercheurs ont recruté un échantillon consécutif de patients dans un délai déterminé. Au total, 128 patients y ont participé : 64 patients ayant des DPC (32 hommes et 32 femmes) et 64 patients témoins ( 32 hommes et 32 femmes). Le même opérateur a réalisé tous les tests. L'électromyographie de l'AIA repose sur la collecte de potentiels d'unités motrices qui mesurent le nombre de modifications au signal et leur amplitude moyenne. L'électromyogramme transfère les données sur un graphique en nuage de points, ce qui permet de comparer les résultats des patients à ceux des sujets en santé.

RÉSULTATS : Chez les patients et les sujets témoins, la sensibilité et la spécificité du test diagnostique proposé avaient une signification clinique marquée. En effet, la sensibilité s'élevait à $83 \%$, et la spécificité, à $100 \%$. Les chercheurs ont observé une valeur prédictive positive de 1 (95\% IC 1 à 1) et une valeur prédictive négative de 0,85 (95\% ICI 0,77 à 0,93). CONCLUSION : L'AIA est un test fiable pour diagnostiquer le SMPP. D'autres études s'imposent pour reproduire les résultats de la présente étude.

entities include chronic bacterial prostatitis (CBP) and chronic nonbacterial prostatitis/chronic pelvic pain syndrome (CNBP/CPPS) (19), interstitial cystitis (IC) (20), levator ani syndrome (21), pudendal nerve entrapment syndrome (PNE) (22), urgency-frequency syndrome (10), endometriosis (23) and vulvodynia (12).

Currently, there is no gold-standard test to confirm MPSPF. Therefore, the aim of the present study was to validate turns-amplitude analysis (TAA) as a diagnostic test for MPSPF in patients with CPP.

\section{METHODS}

The present analysis was a case-control study. A consecutive nonprobability sampling method was used over a specified period of time (February 2011 to October 2012). Patients who had been diagnosed with CPP in the Spanish territory were included in the study. These patients had been referred by specialists from several hospital units to the authors' pelvic pain clinic (Madrid, Spain).

A total of 128 patients were included in the present study (64 patients with CPP [32 men and 32 women] and a control group of 64 patients [ 32 men and 32 women]). The control group was recruited at the Urology Unit of the San Carlos University Hospital in Madrid.

${ }^{1}$ Pelvic Pain Clinic; ${ }^{2}$ The Cemtro Clinic, Neurophysiology Unit; ${ }^{3}$ San Carlos University Hospital, Urology Unit; ${ }^{4}$ La Princesa University

Hospital, Urology Unit; ${ }^{5}$ College of Psychology at the Autonomous University of Madrid, Department of Biostatistics, Madrid, Spain

Correspondence: Dr Fernando Itza, Calle Profesor Waksman nº 8, 3ํA, 28036 Madrid, Spain. Telephone 34-648-846-047,

fax 34-916-342-778, e-mail fitza1981@gmail.com, fitza@arrakis.es

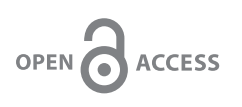

This open-access article is distributed under the terms of the Creative Commons Attribution Non-Commercial License (CC BY-NC) (http:// creativecommons.org/licenses/by-nc/4.0/), which permits reuse, distribution and reproduction of the article, provided that the original work is properly cited and the reuse is restricted to noncommercial purposes. For commercial reuse, contact support@pulsus.com 


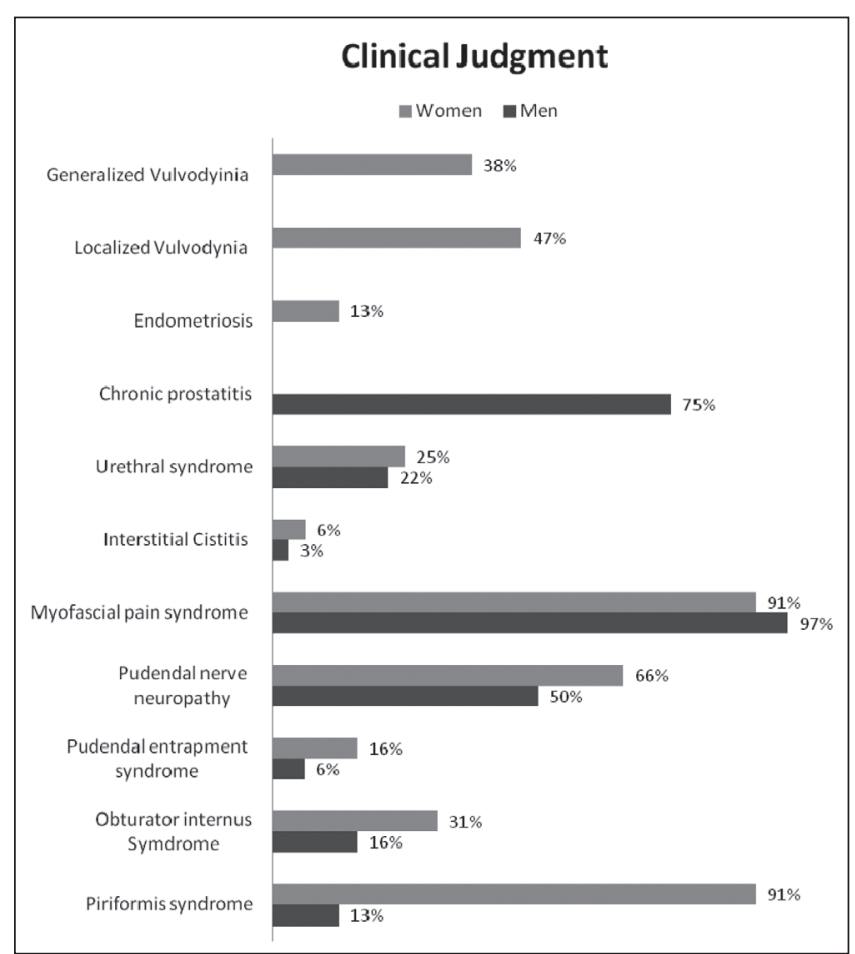

Figure 1) Etiology of chronic pelvic pain among study patients

The patients and control subjects were matched according to sex and age (amplitude range \pm five years) in a 1:1 ratio. The inclusion criteria were Caucasian men and women with symptoms of CPP for $>6$ months. The patients and control subjects underwent a clinical history and physical examination, and TAA indexes, questionnaires and neuropsychological tests were completed. All participants provided written informed consent. In the control group, pain in other parts of the body was not a reason for exclusion. For both groups, the exclusion criteria were the absence of any of the required forms and records.

The patients all had CPP due to one or several etiologies (Figure 1). These etiologies were diagnosed following criteria or recommendations: vulvodynia according to the 2006 International Society for the Study of Vulvovaginal Disease classification (12); myofascial pain syndromes (levator ani syndrome, obturator internus syndrome, piriformis syndrome) in accordance the criteria outlined by Travell and Simons (14); CBP, CNBP/CPPS and IC in accordance with the National Institute of Diabetes and Digestive and Kidney Diseases criteria (19); PNE according to the Nantes criteria (22); urgency-frequency syndrome according to the European Association of Urology guidelines on chronic pelvic pain (1); and endometriosis according to the European Association of Urology guidelines on chronic pelvic pain (1).

For a better understanding and comprehension of the present research work, a descriptive analysis of the sample has been included.

A thorough medical history was obtained from each patient and emphasized aspects of their personal history that could be related to the source of the pain. Patients were also asked about the number of physicians they had previously visited and individuals with whom they had discussed their CPP symptoms.

All patients were examined during a consultation to determine the characteristics and location of the pain. The palpation of TrPs can be used as a screening method for a CPP diagnosis, particularly when the practitioner has experience with $\operatorname{TrPs}$ (24). Applying moderate pressure to a $\operatorname{Tr} \mathrm{P}$ can precisely reproduce a local pain that is frequently perceived by the patient.

External anal sphincter and levator ani muscles were assessed. Pain intensity was assessed using a visual analogue scale (VAS), which has a relatively high interobserver reproducibility.

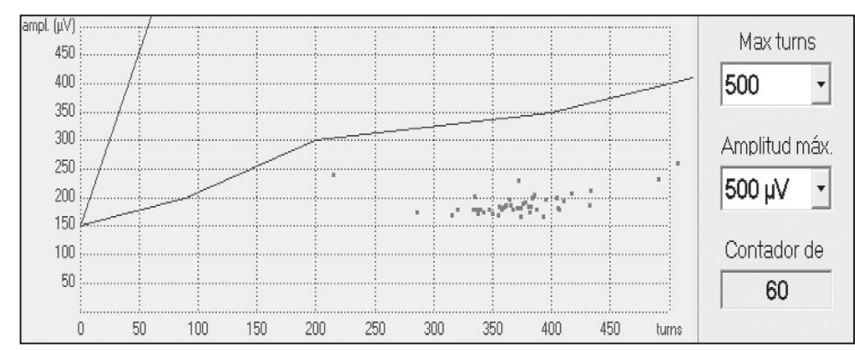

Figure 2) Myofascial pattern: increased turns-amplitude analysis with a horizontal point cloud

Neuropathic pain characteristics were assessed with the Douleur Neuropathique 4 (DN4) questionnaire, which is simple to use and quickly establishes a diagnosis of neuropathic pain. This questionnaire consists of a total of 10 items grouped in four sections. The first seven items are related to the quality of pain (burning, painful cold, electric shocks) and its association to abnormal sensations (tingling, pins and needles, numbness, itching). The other three items are related to neurological examination in the painful area (touch hypoesthesia, pinprick hypoesthesia, tactile allodynia). A score of 1 is given to each positive item and a score of 0 to each negative item. The total score is calculated as the sum of all 10 items, and the cut-off value for the diagnosis of neuropathic pain is a total score of 4 of $10(25)$.

All electromyography (EMG) studies were performed by the same operator using the same equipment (a Micro-Med S.p.A EMG system [Italy] with four channels, ENoG software for electroneuronography and an EMG device). The units of measure are amplitude $(\mu \mathrm{V})$ on the $\mathrm{Y}$ axis and turns (number of turns) on the $\mathrm{X}$ axis (Figure 2).

The operator used a concentric needle electrode with a recording surface.

In all CPP patients and control subjects, the EMG tests were conducted in the levator ani muscle and the external anal sphincter. The mean of the TAA data $(26,27)$ obtained from the EMG device was automatically analyzed by the system. An increase in the corresponding index was considered to be positive, and a decrease in the index was considered to be negative.

The test recorded the electromyographic activity at several locations in the muscle (between six and 10 points), preferably in the area located midway between the motor point and the insertion sites. Each point represents an automatic analysis of a period or epoch. Between 20 (minimum) and 30 tests were performed. In normal conditions, the points are distributed in a 'cloud' that contains $95 \%$ of the points. The test was considered to be pathological when $\geq 10 \%$ of the points were located outside of the cloud (28). Three patterns were observed: a normal pattern with a normal TAA and a point cloud within the standard limits; a myofascial pattern with an increased TAA diagnostic yield and a horizontal point cloud; and a neuropathic pattern with a decreased TAA diagnostic yield and a vertical point cloud outside of the standard limits.

In simple words, the EMG activity of the levator ani muscle and the external anal sphincter is intended to detect myofascial pelvic floor disorders in an objective and reproducible manner. For this, a graph is used as a point cloud.

The EMG test is useful for evaluating the outcome of patients after therapeutic interventions (29).

The results were evaluated as a qualitative dichotomous variable. The variable was considered to be positive when there was an increase in the TAA ratio and negative when there was a decrease in the ratio or when the TAA was a normal in the ratio values. Figure 3 shows three point clouds from the clinical results.

For personal history and pain intensity, a descriptive analysis of the qualitative variables was performed. Quantitative variables are represented by means and SDs. 


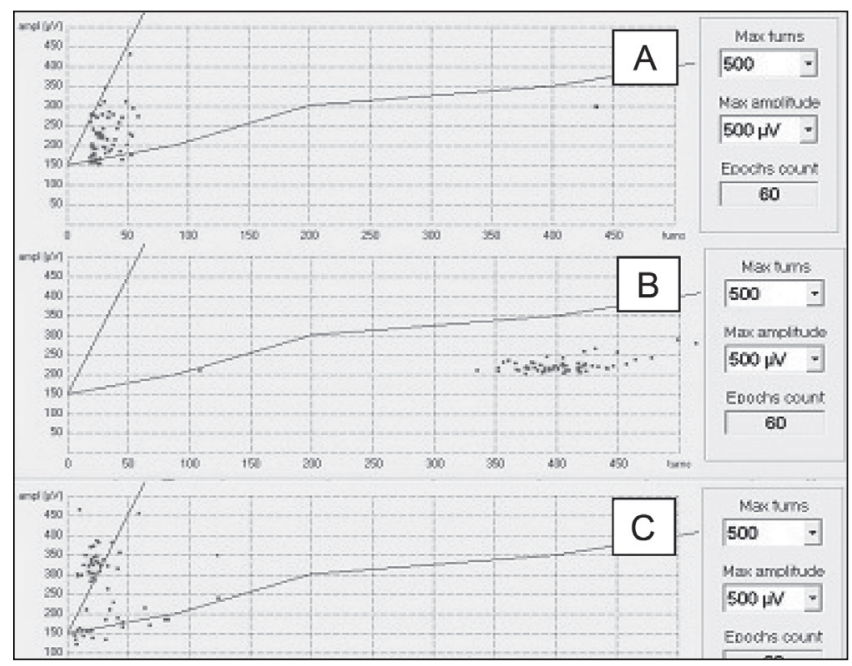

Figure 3) A Normal pattern: normal turns-amplitude analysis (TAA) with a point cloud in the standard limits. B Myofascial pattern: increased TAA with a horizontal point cloud. C Neuropathic pattern: decreased TAA with a vertical point cloud outside of the standard limits

To assess the correlation between MPSPF and TAA, univariate analyses was performed using $\chi^{2}$ or Fisher's exact tests. These tests evaluated the relationship between categorical variables when no more than $25 \%$ of the expected values were $<5$.

The linear correlation between quantitative variables was performed by calculating a nonparametric Spearman's correlation coefficient. To determine the validity of the proposed diagnostic test, the sensitivity, specificity, positive predictive value and negative predictive value were calculated. The processing and analysis of data were performed using SPSS version 16.0.1 (IBM Corporation, USA).

\section{RESULTS}

Data from 64 CPP patients (32 men and 32 women) of different etiologies and 64 control subjects ( 32 men and 32 women) were retrospectively collected.

For men, the mean age was $44.53 \pm 9.61$ years for patients and $45.75 \pm 11.33$ years for control subjects. For women, the mean age was $45.69 \pm 14.65$ years for patients and $48.06 \pm 13.02$ years for control subjects. The mean age of the patient group was $45.1 \pm 12.3$ years, and the mean age of the control group was $46.91 \pm 12.2$ years.

In the present study, a descriptive analysis was used to characterize and clinically profile the typical CPP patient. The clinical profile has the following characteristics:

- Individuals often have competitive personalities, are hyperresponsible and are perfectionists.

- Individuals often engage in primarily sedentary work.

- Individuals, most often women, often have a history of previous abdominal and pelvic surgery.

- Women who give birth at term and undergo episiotomies often experience CPP. A history of vaginal candidiasis was observed for women with CPP in the present study.

- Men often have a history of CBP, CPPS and urethritis. Men participated in sports involving the abdominal muscles, including cycling and exercises to strengthen the abdominal muscles, more often than women.

- Only a few patients had a clinical history of psychiatric disorders. However, most patients had been treated for being emotionally unbalanced, which is a common symptom after which the patients begin to experience CPP.

- Patients typically experience pain when sitting down. In the present study, women complained of dyspareunia at different levels of pain intensity, including deep and shallow pain.
- Ejaculatory, postejaculatory, penile and testicular pain is common in men.

The mean disease progression time was 43.26 months for male patients and 60.62 months for female patients.

The mean number of physicians that had been previously consulted for CPP symptoms was 6.4, and urology was the specialty that was most frequently sought.

On average, women consulted 10 physicians, most often gynecologists and urologists.

Using the VAS, all patients with CPP were asked about the severity or intensity of their pain. For men, the mean VAS intensity was $5.43 \pm 2.29$ for patients and $0.9 \pm 1.2$ for control subjects. For women, the mean VAS intensity was $6.89 \pm 1.89$ for patients and $1.7 \pm 1.8$ for control subjects.

All CPP patients completed the DN4 questionnaire to assess neuropathic pain characteristics. For men, the mean DN4 scores were $4.53 \pm 2.2$ for patients and $0.25 \pm 0.5$ for control subjects. For women, the mean DN4 scores were $4.44 \pm 2.2$ for patients and $0.78 \pm 0.95$ for control subjects.

In respect of the unique objective of this work, the following data were analyzed with the followings results.

For men, a positive test (an increased TAA turns/amplitude ratio) was observed in $28(87.5 \%)$ patients, and a negative test was observed in $32(100 \%)$ control subjects. For women, a positive test was observed in $24(75 \%)$ patients, and a negative test was observed in $32(100 \%)$ control subjects. For the diagnostic test, there were statistically significant differences between the patients and control subjects.

With respect to the relationship between MPSPF and the TAA, none of the control subjects and $86 \%$ of the patients had an increased turns/amplitude ratio $(\mathrm{P}<0.001)$; the correlation between MPSPF and TAA was 0.66 . The sensitivity of the diagnostic test was $83 \%$ and the specificity was $100 \%$. The positive predictive value was 1 ( $95 \%$ CI 1 to 1$)$, and the negative predictive value was 0.85 (95\% CI 0.77 to 0.93 ).

No significant differences were found between men and women, but there was a slightly higher $\chi^{2}$ statistic for men than for women ( 52 versus 46.3 ). The sensitivity was $88 \%$ for women and $78 \%$ for men, and the specificity was $100 \%$ for women and men.

\section{DISCUSSION}

The present study highlights the myofascial component as a major factor in the etiology and clinical manifestation of various urological, gynecological and neurological diseases that result in CPP.

Potts and O'Dougherty (30) reported the emergence of myofascial syndrome as an important factor in the multifactorial etiology that explains this type of CPP in CBP and CPPS. In a study involving 103 men, Zermann et al (31) were the first to correlate CBP with MPSPF; $92.2 \%$ of the men with CNBP/CPPS exhibited pelvic floor dysfunction.

Patients with IC may complain of urethral, vaginal or rectal pain; pain in the lower back and thighs; and pain during sexual intercourse (11). In males, pain in the penis or scrotum is often associated with myofascial disorders (32).

Myofascial abnormalities and TrPs in the superficial and deep muscles of the perineum (33) may cause, aggravate or maintain a variety of chronic symptoms that are related to pathologies in the bladder, urethra, prostate and colon.

Similarly, $15 \%$ of women with CPP display evidence of an abdominal myofascial alteration (30).

In a study of four cases of CPP in patients with IC and irritative bladder symptoms, Doggweiler-Wiygul (34) found that the patients' TrPs in the piriformis, gluteal and internal obturator muscles could be treated by infiltration and stretching. To verify these points, the author relied on the local spasms of the perineal muscles and the referred pain on palpation.

A more serious pathology that requires surgical treatment is PNE, which is also related to MPSPF and causes similar symptoms (35). 
Vulvodynia also affects TrPs and can increase the tone of the pelvic floor muscles. Using a series of neurophysiological tests, Glazer (36) found relationships among high muscle tone, spasms and poor balance between contraction and relaxation for women with vulvar pain; these relationships were absent in the control group.

Endometriosis has also been associated with MPSPF. Jarrell (37) found that myofascial dysfunction is common in the presence of endometriosis and visceral disease.

For palpation, we observed various alterations of the intrapelvic muscles, abdominal muscles and lower limbs. For deep palpation, we found hyperirritability, immobility, tenderness, edema, tension and muscle spasms. These findings are consistent with a study by Anderson et al (38) involving areas where TrPs are localized and in the referred pain irradiation areas.

In patients with CPP, it is important to explore and palpate all muscles and fascia, bone structures, ligamentous attachments, accessible nerve structures and subcutaneous connective tissues.

Unfortunately, TrPs cannot be identified by laboratory tests and do not have distinctive histological characteristics, although a preliminary study has used ultrasound imaging to characterize TrPs and the surrounding soft tissue (39).

Currently, MPSPF is diagnosed using clinical history, measurements of pain intensity and manual/digital muscle exploratory techniques. Hong et al (24) used a simple method to induce pain: pressing with the fingers until the patient's fingernail beds turned pale. This occurs when a force of $3 \mathrm{~kg} / \mathrm{cm}^{2}$ to $4 \mathrm{~kg} / \mathrm{cm}^{2}$ is applied (24). The diagnostic technique of dry needling is also known and involves inserting a needle into a $\operatorname{TrP}$, which causes a local spasmodic response. However, according to a systematic review by Lucas et al (40), these two diagnostic methods are biased.

Jarrell et al (41) reported the use of three bedside tests (cutaneous allodynia, myofascial TrPs and reduced pain thresholds) in discriminating visceral pain from somatic pain among women with chronic pelvic pain. They concluded that these tests are easily applied and well tolerated; furthermore, the tests could differentiate myofascial pain in the pelvis due to visceral disease versus somatic illness.

In the same line, Giamberardino et al (42) described that visceral disorders such as kidney stones and endometriosis can all produce $\operatorname{Tr} \mathrm{P}$

\section{REFERENCES}

1. Fall M, Baranowski AP, Elneil S, et al. EAU guidelines on chronic pelvic pain. European Association of Urology. Eur Urol 2010;57:35-48.

2. Bartoletti R, Cai T, Mondaini N, et al. Italian Prostatitis Study Group. Prevalence, incidence estimation, risk factors and characterization of chronic prostatitis/chronic pelvic pain syndrome in urological hospital outpatients in Italy: Results of a multicenter case-control observational study. J Urol 2007;178:2411-5.

3. Walter EA, Katon WF. The prevalence of chronic pain and irritable bowel syndrome in two university clinics. Psychosom Obstet Gynaecol 1991;12:66-9.

4. Mathias SD, Kupperman M, Liberman R, Steege JF, Lipshutz RC. Chronic pelvic pain: Prevalence, health-related quality of life, and economic correlates. Obstet Gynecol 1996;87:321-7.

5. Pitts MK, Ferris JA, Smith AMA, Shelley JM, Richters J. Prevalence and correlates of three types of pelvic pain in a nationally representative sample of Australian women. Med J Aust 2008;189:138-43.

6. Schaeffer AJ. Epidemiology and evaluation of chronic pelvic pain syndrome in men. Int J Antimicrob Agents 2008;(31 Suppl):S108-11.

7. Churakov AA, Popkov VM, Zemskov SP, Glybochko PV, Bliumberg BI. Combined physiotherapy of chronic infectious prostatitis. Urologia 2007;61-5.

8. Curtis Nickel J, Baranowski AP, Pontari M, Berger RE, Tripp DA. Management of men diagnosed with chronic prostatitis/chronic pelvic pain syndrome who have failed traditional management. Rev Urol 2007;9:63-72.

9. Fenton BW, Palmieri P, Diantonio G, Vongruenigen V. Application of Patient-Reported Outcomes Measurement Information System to chronic pelvic pain. J Minim Invasive Gynecol 2011;18:189-93. pain in body wall regions of referred pain. These may appear similar to primary myofascial pain syndromes when they are, in fact, secondary pain syndromes, representing viscerosomatic pain syndromes.

Electrophysiological studies constitute other important and more objective techniques, but they are rarely prescribed in routine practice because the information they provide is not completely specific.

Hubbard and Berkoff (43) have described a nonspecific electrodiagnostic version of the myofascial syndrome; they reported a feature of the electrical activity, common for all $\mathrm{TrPs}$, in which potentials were characterised by a high-frequency spike. Simons et al (44) detected another feature that involved a low-amplitude noise that was always present in the data; the noise was considered to be a spontaneous electrical activity.

Recently, Partanen et al (45) found that taut bands may be local contraction points in skeletal motor units, which may be caused by a sustained reflex impulse in the muscle spindles. In EMG, this can be observed as complex repetitive discharges; thus, we can deduce that TrPs are related to painful muscle spindles in the taut bands.

While these are important findings that support a MPSPF diagnosis, they provide insufficient predictive power to constitute a diagnostic test. Indeed, despite all of the clinical and diagnostic data that have been obtained using different procedures, these data do not provide a more objective diagnosis of MPSPF in patients with CPP.

The present study has demonstrated that TAA is a reliable diagnostic test to detect MPSPF and has estimated the test's sensitivity, specificity, and positive and negative predictive values.

The results of research similar to the present study are usually compared with a gold standard diagnostic test; however, for MPSPF, no such test exists. Further studies are needed to confirm and reproduce these results.

DISCLOSURES: The authors have no conflicts of interest to declare.

ACKNOWLEDGEMENTS: The authors thank the study participants; these participants have helped patients who experience chronic pelvic pain.
10. Powell CR, Kreder KJ. Long-term outcomes of urgency-frequency syndrome due to painful bladder syndrome treated with sacral neuromodulation and analysis of failures. J Urol 2010;183:173-6.

11. Bassaly R, Tidwell N, Bertolino S, Hoyte L, Downes K, Hart S. Myofascial pain and pelvic floor dysfunction in patients with interstitial cystitis. Int Urogynecol J Pelvic Floor Dysfunct 2011;22:413-8.

12. Itza F, Zarza D, Gómez-Sancha F, Salinas J, Bautrant E. Update on the diagnosis and treatment of vulvodynia. Actas Urol Esp 2012;36:431-8

13. Forrest JB, Nickel JC, Moldwin RM. Chronic prostatitis/chronic pelvic pain syndrome and male interstitial cystitis: Enigmas and opportunities. Urology 2007;69(4 Suppl):60-3.

14. Travell J, Simons D. Myofascial Pain and Dysfunction: The Trigger Point Manual, Volume 2. The Lower Extremities. Baltimore: Lippincott Williams \& Wilkins 1999;137-63.

15. Pukall CF, Baron M, Amsel R, Khalifé S, Binik YM. Tender point examination in women with vulvar vestibulitis syndrome. Clin J Pain 2006;22:601-9.

16. Peltier J. Anatomical basis of transgluteal approach for pudendal neuralgia and operative technique. Surg Radiol Anat 2013;35:609-14.

17. Moldwin RM, Fariello JY. Myofascial trigger points of the pelvic floor: Associations with urological pain syndromes and treatment strategies including injection therapy. Curr Urol Rep 2013;14:409-17.

18. Itza F, Zarza D, Serra L, Gómez-Sancha F, Salinas J, Allona-Almagro A. Myofascial pain syndrome in the pelvic floor: A common urological condition. Actas Urol Esp 2010;34:318-26.

19. McNaughton-Collins M, Joyce GF, Wise M, Pontari MA. Prostatitis. In: Litwin MS, Saigal CS, eds. Urologic Diseases in America. U.S. Department of Health and Human Services, Public Health Service, National Institutes of Health, National Institute of 
Diabetes and Digestive and Kidney Diseases. Washington, DC: U.S. Government Publishing Office, 2007; NIH Publication No. 07-5512;9-42.

20. Lee JD, Lee MH. Activation of extrinsic apoptotic pathway from bladder biopsy in patients with interstitial cystitis/painful bladder syndrome. Urology 2013;82:1451

21. Chiarioni G. Treatment of levator ani syndrome: Update and future developments. Recenti Prog Med 2011;102:196-201.

22. Robert R, Labat JJ, Khalfallah M, Louppe JM, Riant T, Hamel O. Pudendal nerve surgery in the management of chronic pelvic and perineal pain. Prog Urol 2010;20:1084-8

23. Yong PJ, Sutton C, Suen M, Williams C. Endovaginal ultrasoundassisted pain mapping in endometriosis and chronic pelvic pain. J Obstet Gynaecol 2013;33:715-9.

24. Hong CZ, Kuan TS, Chen JT, Chen SM. Referred pain elicited by palpation and by needling of myofascial trigger points: A comparison. Arch Phys Med Rehabil 1997;78:957-60.

25. Bouhassira D, Attal N. All in one: Is it possible to assess all dimensions of any pain with a simple questionnaire? Pain 2009;144:7-8.

26. Masanori H, Hiroaki N, Hiroyuky H, Masuo S, Yukihisa Y. Diagnostic value of turns-amplitude analysis in neuromuscular disease. J Orthop Sci 1997;2:283-8.

27. Fuglsang-Frederiksen A, Pugdahl K. Current status on electrodiagnostic standards and guidelines in neuromuscular disorders. Clin Neurophysiol 2011;122:440-55.

28. Nandedkar SD, Sanders DB, Stalberg EV. On the shape of the normal turns--amplitude cloud. Muscle Nerve 1991;14:8-13.

29. Werdelin L, Dalager T, Fuglsang-Frederiksen A, et al. The utility of EMG interference pattern analysis in botulinum toxin treatment of torticollis: A randomised, controlled and blinded study. Clin Neurophysiol 2011;122:2305-9.

30. Potts JM, O'Dougherty E. Pelvic floor physical therapy for patients with prostatitis. Curr Urol Rep 2000;1:155-8.

31. Zermann DH, Ishigooka M, Doggweiler R, Schmidt RA. Chronic prostatitis: A myofascial pain syndrome? Infect Urol 1999;12:84-88.

32. Wesselmann U, Magora F, Ratner V. Pain of urogenital origin. Rev Soc Esp Dolor 2001;8:428-32.
33. Chaitow L. Chronic pelvic pain: Pelvic floor problems, sacro-iliac dysfunction and the triggers point connection. J Bodyw Mov Ther 2007;10:10-6.

34. Doggweiler-Wiygul R. Interstitial cystitis, pelvic pain, and relationship to myofascial pain and dysfunction: A report on four patients. World J Urol 2002;20:310-4.

35. Itza Santos F, Salinas J, Zarza D, Gómez Sancha F,

Allona Almagro A. Update in pudendal nerve entrapment syndrome: An approach anatomic-surgical, diagnostic and therapeutic. Actas Urol Esp 2010;34:500-9.

36. Glazer HI. Dysesthetic vulvodynia. Long-term follow-up after treatment with surface electromyography-assisted pelvic floor muscle rehabilitation. J Reprod Med 2000;45:798-802.

37. Jarrell J. Endometriosis and abdominal myofascial pain in adults and adolescents. Curr Pain Headache Rep 2011 Oct;15:368-76.

38. Anderson RU, Sawyer T, Wise D, Morey A, Nathanson BH. Painful myofascial trigger points and pain sites in men with chronic prostatitis/chronic pelvic pain syndrome. J Urol 2009;182:2753-8.

39. Sikdar S, Shah JP, Gebreab T, et al. Novel applications of ultrasound technology to visualize and characterize myofascial trigger points and surrounding soft tissue. Arch Phys Med Rehabil 2009;90:1829-38.

40. Lucas N, Macaskill P, Irwig L, Moran R, Bogduk N. Reliability of physical examination for diagnosis of myofascial trigger points: A systematic review of the literature. Clin J Pain 2009;25:80-9.

41. Jarrell J, Giamberardino MA, Robert M, Nasr-Esfahani M. Bedside testing for chronic pelvic pain: Discriminating visceral from somatic pain. Pain Res Treat 2011;2011:692102.

42. Giamberardino MA, Berkley KJ, Affaitati G, et al. Influence of endometriosis on pain behaviors and muscle hyperalgesia induced by a ureteral calculosis in female rats. Pain 2002;95:247-57.

43. Hubbard DR, Berkoff GM. Myofascial trigger points show spontaneous needle EMG activity. Spine 1993;18:1803-7.

44. Simons DG, Hong CZ, Simons LS. Endplate potentials are common to midfiber myofascial trigger points. Am J Phys Med Rehabil 2002;81:212-22.

45. Partanen JV, Ojala TA, Arokoski JP. Myofascial syndrome and pain: A neurophysiological approach. Pathophysiology 2010;17:19-28. 


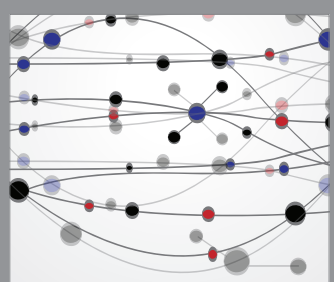

The Scientific World Journal
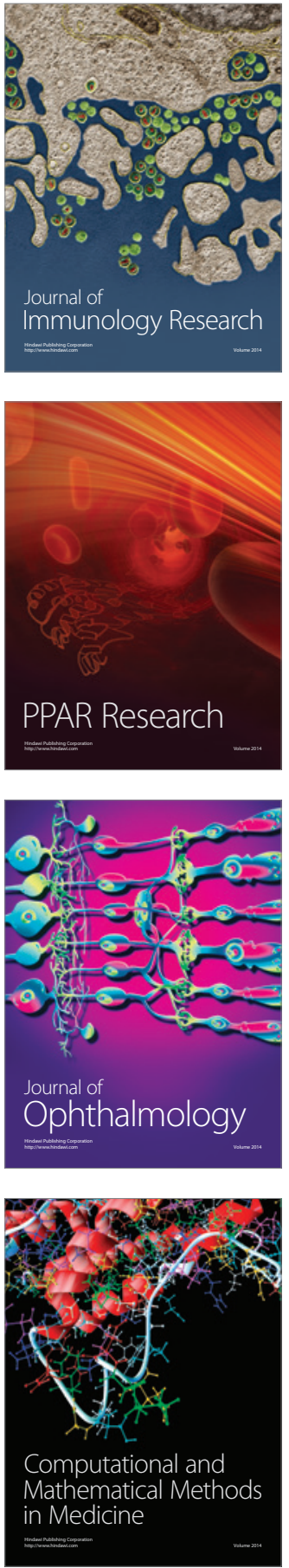

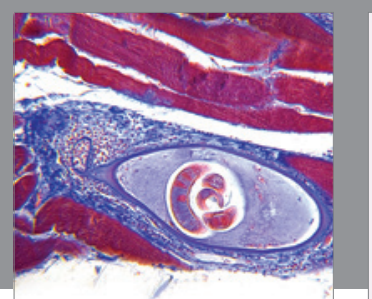

Gastroenterology Research and Practice

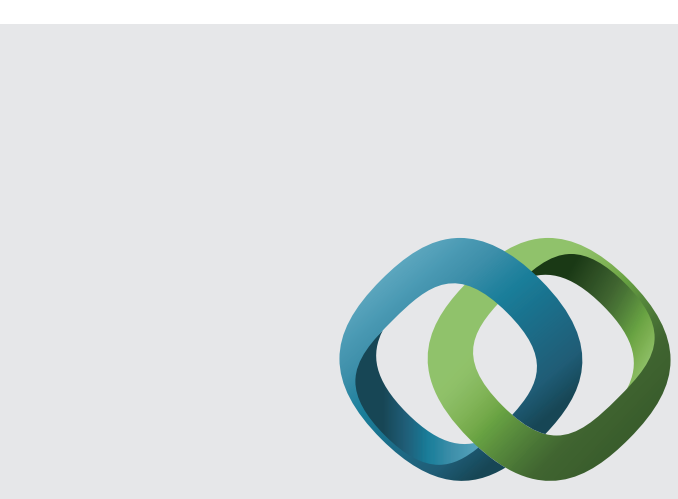

\section{Hindawi}

Submit your manuscripts at

http://www.hindawi.com
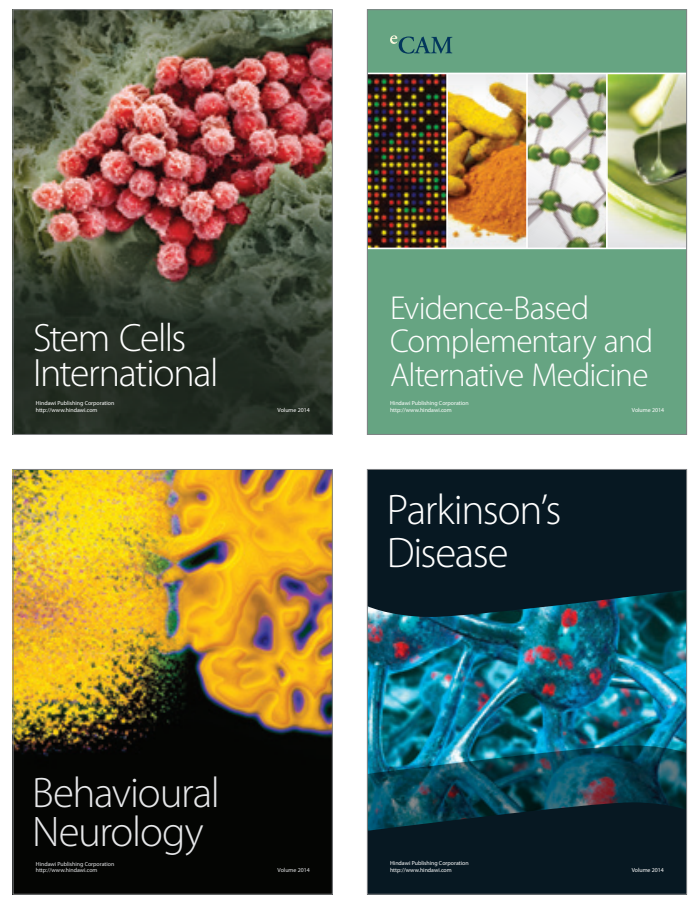
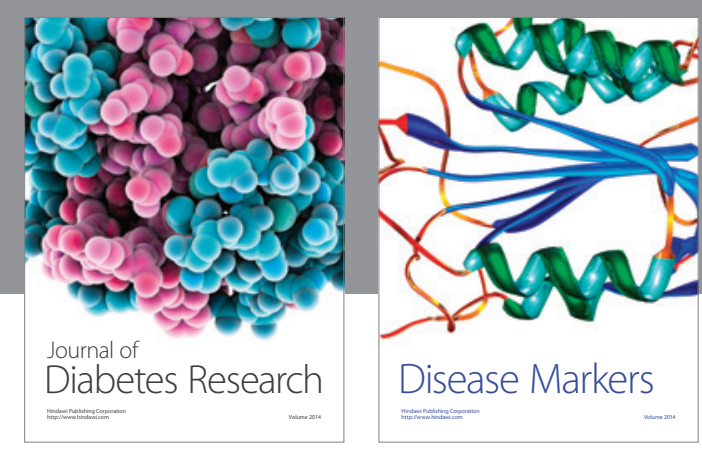

Disease Markers
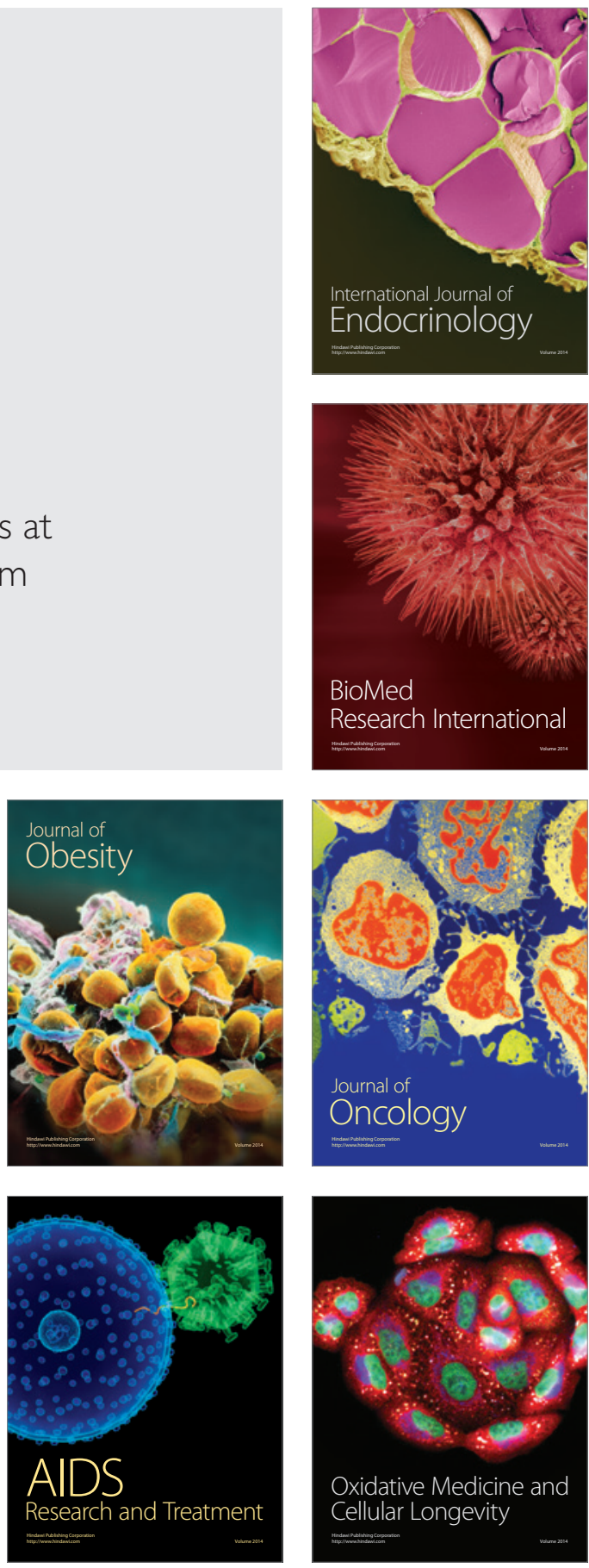